\title{
Ácidos grasos de cadena corta y media como precursores para inhibir los síntomas del coronavirus
}

\section{Short and medium chain fatty acids as precursors for inhibiting coronavirus symptoms}

\author{
Mateos Islas Mario ${ }^{a}$, Ventura Pérez Paola ${ }^{b}$, Ariza Ortega José Alberto ${ }^{c}$.
}

\begin{abstract}
:
Short chain fatty acids (acetic C2:0, propionic C3:0 and butyric C4:0), medium (caproic C6:0, caprylic C8:0, capric C10:0 and lauric $\mathrm{C} 12: 0$ ), originate from the fermentation of dietary fiber intake, carried out by microorganisms in the intestinal tract, and they are found in some foods, its consumption exerts an anti-inflammatory and antiviral effect, due to of reducing the expression of proinflammatory cytokines such as TNF- $\alpha$, IL-6, IL-12 and the mediation of IL-10 and are antimicrobial against fungi, viruses and bacteria; because they destroy their cell membrane respectively. The main purpose of this work was to review the effect of short and medium chain fatty acids, as precursors to inhibit the symptoms of coronavirus. Many scientific researchs has been carried out through electronic databases and studies have shown that C2:0, C3:0 and C4:0 at a concentration of $200 \mathrm{mM}, 50 \mathrm{mM}$ and $5 \mathrm{mM}$ respectively, reduce inflammation by means of activation of various GPCRs, which suppress the expression of adhesion molecules in inflammatory cells and endothelial cells, preventing monocyte chemotaxis at the inflammatory site. While C12:0 at $250 \mathrm{mM}$ is antimicrobial and inhibits the late maturation stage of the virus replication cycle. In conclusion, the intake of C2:0, C3:0, C4:0 and C12:0 could reduce or inhibit the symptoms of the coronavirus family, such as COVID-19.
\end{abstract}

Keywords:

Anti-inflammatory, antimicrobial, cytokine, coronavirus, fatty acids

\section{Resumen:}

Los ácidos grasos de cadena corta (acético C2:0, propiónico C3:0 y butírico C4:0), media (caproico C6:0, caprílico C8:0, cáprico C10:0 y láurico C12:0), se originan por la fermentación de la ingesta de fibra en la dieta, llevada a cabo por los microorganismos en el tracto intestinal, y se encuentran en algunos alimentos, su consumo ejerce un efecto antiinflamatorio y antiviral, debido a que reducen la expresión de citocinas proinflamatorias como TNF- $\alpha$, IL-6 e IL-12 y la mediación de IL-10 y son antimicrobianos contra hongos, virus y bacterias, debido a que destruyen su membrana celular respectivamente. El objetivo principal de este trabajo fue revisar el efecto de los ácidos grasos de cadena corta y media, como precursores para inhibir los síntomas del coronavirus. Numerosas investigaciones científicas se han realizado a través de bases de datos electrónicas y los estudios han demostrado que los C2:0, C3:0 y C4:0 a una concentración de $200 \mathrm{mM}, 50 \mathrm{mM}$ y $5 \mathrm{mM}$ respectivamente, reducen la inflamación mediante la activación de varios receptores acoplados a la proteína G (GPCR), que suprimen la expresión de moléculas de adhesión en células inflamatorias y células endoteliales, previniendo la quimiotaxis de monocitos en el sitio inflamatorio. Mientras que el C12:0 a una concentración de 250 mM presenta una actividad antimicrobiana e inhibe la etapa de maduración tardía del ciclo de replicación del virus. En conclusión, la ingesta de C2:0, C3:0, C4:0 y C12:0 podría disminuir o inhibir los síntomas de la familia del coronavirus, como es el COVID-19.

\section{Palabras Clave:}

Ácidos grasos, antiinflamatorio, antimicrobiano, citocinas, coronavirus

En la naturaleza hay microorganismos patógenos para los humanos, como son los coronavirus, genomas de Introducción virus de ARN monocatenario con sentido positivo, no

\footnotetext{
Autor de correspondencia, Universidad Autónoma del Estado de Hidalgo, https://orcid.org/0000-0001-6988-6696, email: ma346475@uaeh.edu.mx

b Universidad Autónoma del Estado de Hidalgo, https://orcid.org/0000-0002-0613-7847, email: ve337803@uaeh.edu.mx

${ }^{c}$ Universidad Autónoma del Estado de Hidalgo, https://orcid.org/0000-0002-2163-4593, email: jose190375@ hotmail.com
} 
segmentados y envueltos en un tamaño que varía de 26 a 32 kilobases, siendo el genoma de ARN viral más grande que se conoce. ${ }^{1}$ Se caracterizan por dos grupos de proteínas: proteínas estructurales (espiga (S), envoltura (E), nucleocápside (N) y membrana (M) y proteínas no estructurales (llamadas nsp1-nsp16). Estas proteínas son necesarias en diferentes etapas del ciclo de replicación del virus y muchas de ellas son objetivos potenciales para la terapia o el desarrollo de vacunas. ${ }^{2}$

En diciembre de 2019, comenzó un brote de neumonía de origen desconocido en la provincia China de Hubei y después de numerosos estudios, se identificó un nuevo síndrome respiratorio agudo severo coronavirus 2 (SARS-CoV-2) o coronavirus-19 (COVID-19), ${ }^{3}$ este nuevo coronavirus humano, pertenece a la clasificación de virus del Grupo IV de Baltimore, que incluye el virus del Nilo Occidental, virus del dengue, rinovirus, hepacivirus $\mathrm{C}$ (virus de la hepatitis $\mathrm{C}$ ), coronavirus del síndrome respiratorio agudo severo (SARS-CoV) y el coronavirus del síndrome respiratorio de Oriente Medio (MERS-CoV). Estos se comportan de la misma manera y comparten un genoma similar, utilizan ARN monocatenario de sentido positivo largo $(10,000$ a 30,000 pb) como material genético. ${ }^{2}$

La preocupación a nivel mundial recae en su fácil modo de transmisión, ya que se ha reportado que COVID-19 se puede transmitir de persona a persona, a través del contacto directo con un individuo infectado o cuando una persona tose o estornuda (se generan pequeñas gotas suspendidas en el aire y se pueden desplazar hasta 1.8 metros), contacto con superficies contaminadas 0 fómites. ${ }^{3}$ Los síntomas de la enfermedad pueden ser desde infecciones asintomáticas, hasta infecciones leves (tipo resfriado común), moderadas y finalmente graves, donde se requiere hospitalización (para asegurar apoyo respiratorio asistido y otros tratamientos médicos hasta su recuperación o posible muerte). ${ }^{4}$ Los síntomas más comunes para la infección de COVID-19, suelen ir desde dolor de garganta, fatiga, tos seca, mialgia y fiebre. No obstante, algunos pacientes también presentan dolor de cabeza, vómito, diarrea, disnea, producción de esputo y linfopenia, los cuales pueden aparecer en un período de 5.2 días, tiempo promedio de incubación del coronavirus. ${ }^{5}$

En algunos pacientes se puede activar la linfohistiocitosis hemofagocítica secundaria, que es un incremento de citocinas inflamatorias que ejercen una actividad en varios tejidos y células inmunes. ${ }^{6}$ Estos niveles de citocinas en el organismo, originan disfunción endotelial, daño vascular y desregulación paracrina/metabólica, lo que daña múltiples sistemas orgánicos. ${ }^{7}$

En pacientes graves, se han observado niveles significativamente más altos de citocinas inflamatorias, quimiocinas y genes estimulados por interferón, o mejor conocido como "tormenta de citocinas". Se ha demostrado que el incremento de citocinas da como resultado la entrada de varias células inmunes como macrófagos, neutrófilos y células T desde la circulación al sitio de infección, causando efectos destructivos en el tejido, daño en la barrera vascular, daño capilar, daño alveolar difuso, falla multiorgánica y finalmente puede causar la muerte. ${ }^{8}$ En particular, IL-1 $1 \beta$, IL-6 e IL-10 son las tres citocinas más elevadas en los casos graves. Esto fue demostrado por Yang et al. $(2020)^{9}$ en un estudio en el cual se observaron niveles elevados de citocinas incluidas IL2, IL-4, IL-6, IL-10, TNF- $\alpha$ e IFN-y, (16.66, $16.87,>14031.14,7451.48,155.53$ y $453.95(\mathrm{pg} / \mathrm{mL})$ respectivamente) en casos graves y críticos de COVID19, sin embargo, los pacientes con niveles de citocinas superiores a $200 \mathrm{pg} / \mathrm{mL}$ que estaban predominantes en los grupos de IL-6 e IL-10, mostraron un aumento dramático en los niveles de $97.0 \%$ y $100.0 \%$ respectivamente. Otro estudio realizado por Chen et al. $(2020)^{10}$ en 21 pacientes con un cuadro clínico moderado y severo, indicó que las concentraciones de citocinas séricas como la interleucina $2 \mathrm{R}$ (IL-2R), IL-6, IL-10 y factor de necrosis tumoral $\alpha$ (TNF- $\alpha$ ) aumentaron en el cuadro clínico severo comparado con los pacientes con un cuadro moderado.

Los tratamientos farmacéuticos que se han propuesto, no son específicos para tratar COVID-19 o prevenir la infección por 2019-nCoV. ${ }^{3}$ Por lo anterior, para minimizar el daño en la salud originada por este microorganismo, se sugiere el consumo de alimentos que ayudan a prevenir y a inhibir las reacciones químicas por el coronavirus.

Se ha reportado que el ácido acético (36\%), propiónico $(9 \%)$ y butírico (2\%), influyen en la respuesta inmune local, en la mucosa y luz intestinal, y sistémicamente, en todos los órganos corporales, manteniendo así una homeostasis inmune saludable y autoinmunidad. ${ }^{11,12}$ Dependiendo de su concentración, pueden modular la migración de células inmunes a los sitios inflamatorios, afectando la adhesión y las funciones celulares como la proliferación y apoptosis. ${ }^{13}$

Por lo tanto, el objetivo del presente trabajo fue revisar información sobre la importancia que tienen los ácidos grasos de cadena corta y media, en la respuesta antiinflamatoria y antiviral, con énfasis en el coronavirus.

\section{Ácidos grasos de cadena corta y media}

Los ácidos grasos de cadena corta y media, son ácidos grasos monocarboxílicos, que tienen menos de 6 átomos de carbono (en conformaciones de cadenas lineal 0 ramificada) y con una longitud en su cadena de 6 a 12 átomos de carbonos respectivamente. ${ }^{14,15}$

Los ácidos grasos de cadena corta más estudiados, son el ácido acético (C2:0), propiónico (C3:0) y butírico (C4:0) (Figura 1).

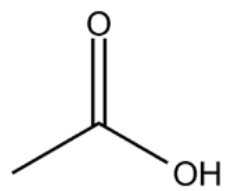

Ácido acético $(\mathrm{CH} 3 \mathrm{COOH})$

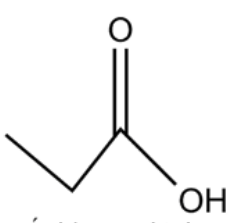

Ácido propiónico $\left(\mathrm{C}_{3} \mathrm{H}_{6} \mathrm{O}_{2}\right)$

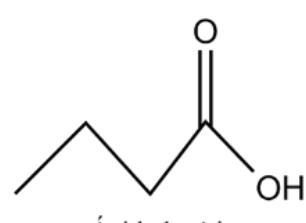

Ácido butírico $\left(\mathrm{C}_{4} \mathrm{H}_{8} \mathrm{O}_{2}\right)$ 
Figura 1. Estructura y fórmula química de los ácidos grasos de cadena corta, realizada con Chem $3 D$ versión 17.0.0.206 (Perkin Elmer Informatics, Inc. 1998 - 2017).

Estos ácidos grasos, se encuentran en el tracto intestinal a una concentración de 70 a $140 \mathrm{mM}$ en colon proximal y de 20 a $70 \mathrm{mM}$ en colon distal, teniendo una proporción aproximada de 60:20:2016 para acetato, propionato y butirato respectivamente, debido a que las poblaciones de bacterias que se localizan en este órgano, degradan los sacáridos no digeribles y otras moléculas, durante el proceso de fermentación. ${ }^{17}$ También se encuentran en alimentos, como se muestra en la Tabla 1.

TABLA 1. Ácidos grasos de cadena corta de algunas fuentes dietéticas

\begin{tabular}{lccc}
\hline & \multicolumn{3}{c}{ Concentración (g/100g) } \\
\multicolumn{1}{c}{ Alimentos } & $\mathrm{C} 2: 0$ & $\mathrm{C} 3: 0$ & $\mathrm{C} 4: 0$ \\
\hline Anguila & - & 0.0011 & - \\
Carpa cruciana & - & 0.03 & - \\
Vinagre & 0.75 & - & - \\
Leche de vaca entera & - & - & 0.10 \\
Queso de cabra & - & - & $1.0-1.8$ \\
Queso parmesano & - & - & 1.50 \\
Mantequilla & - & - & 3.00 \\
\hline
\end{tabular}

Acético (C2:0), propiónico (C3:0) y butírico (C4:0). Modificado de 18, 19, 20

Por otro lado, en la clasificación de ácidos grasos de cadena media, se encuentran los ácidos grasos caproico (C6:0), caprílico (C8:0), cáprico (C10:0) y láurico (C12:0) (Figura 2), donde C12:0 a una concentración de 5.00\%, inhibió el crecimiento tanto de bacterias Gram positivas como Gram negativas, y mejoró su inhibición a concentraciones de $15.00 \%$ y $20.00 \%$. ${ }^{21}$ Mientras que el sinergismo entre C8:0 y C10:0, ejerció un efecto antibacteriano en Escherichia coli, Streptococcus suis, Salmonella poona y Clostridium perfringens. ${ }^{22}$
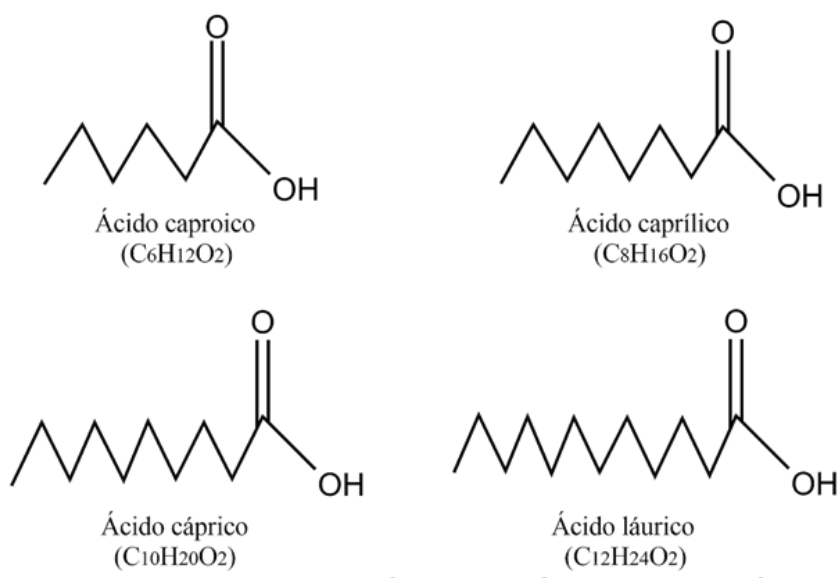

Figura 2. Estructura y fórmula química de los ácidos grasos de cadena media, realizada con Chem $3 D$ versión 17.0.0.206 (Perkin Elmer Informatics, Inc. 1998-2017).

Los aceites de coco y palmiste, son los que presentan una mayor concentración de estos constituyentes (Tabla 2). El aceite de coco, contiene un $90.00 \%$ de ácidos grasos saturados, donde el $60.00 \%$ son ácidos grasos de cadena media ${ }^{23}$ como láurico $(49.00 \%)$, caprílico $(8.00 \%)$ y cáprico $(7.00 \%) .{ }^{24}$ Mientras que en el aceite de palmiste, tiene un $82.00 \%$ de ácidos saturados y un $50.00 \%$ de su composición son ácidos grasos de cadena media ${ }^{25}$ como láurico $(48.00 \%)$, cáprico $(3.50 \%)$, caprílico $(3.30 \%)$ y caproico $(0.20 \%){ }^{26}$ A continuación, en la Tabla 2 se muestran algunos alimentos que son fuente de ácidos grasos de cadena media.

TABLA 2. Ácidos grasos de cadena media de algunos alimentos

$$
\text { Concentración (g/100g) }
$$

Alimentos

$$
\text { C6:0 }
$$$$
\text { C8:0 }
$$

C10:0

Aceite de coco

$\begin{array}{cccc}- & 7.50 & 6.00 & 47.00 \\ 0.76 & 4.09 & 3.61 & 47.53\end{array}$

Aceites de palmiste

0.76

Aceite de palma

$0 \quad 0$

0

0.45
Caproico (C6:0), caprílico (C8:0), cáprico (C10:0) y láurico (C12:0). Modificado de 27

\section{Metabolismo de los ácidos grasos de cadena corta y media}

El metabolismo, es el conjunto de reacciones bioquímicas que tienen lugar en un organismo vivo, y se puede llevar a cabo en presencia 0 en ausencia de oxígeno (fermentación). La fermentación, es un proceso catabólico de oxidación incompleta, cuyo producto final es un compuesto orgánico. Existen diferentes tipos de fermentación, una de ellas es la fermentación natural, que se origina cuando las condiciones ambientales permiten la interacción entre los microorganismos y los sustratos orgánicos, como lo es la fibra, que está constituida por hidratos de carbono complejos y lignina. Cuando las fibras dietéticas llegan al intestino grueso y son catabolizadas por la microflora colónica, se producen productos anabólicos de fermentación, como lo son los ácidos grasos de cadena corta, hidrógeno, dióxido de carbono y metano. Los ácidos grasos de cadena corta como el ácido acético C2:0 (60.00\%), propiónico C3:0 (20.00\%) y butírico C4:0 $(20.00 \%)$, pueden ser usados como fuente de energía y tener otras funciones biológicas sobre el organismo. ${ }^{28}$

El ácido acético es el más abundante en el colon, se utiliza principalmente en los tejidos periféricos, y se forma por la metilación reductora de $\mathrm{CO}_{2}{ }^{14}$ Por otra parte, el ácido propiónico se utiliza como sustancia anabólica en el hígado, es producido a través de la ruta metilmalónicaCoA (ruta dicarboxílica) en la que se genera a partir del lactato, que es suministrado por las bacterias de fermentación ${ }^{14}$. El ácido butírico, se forma por la condensación de dos moléculas de acetil-CoA para formar acetoacetil-CoA, seguido de una conversión 
reductora de acetoacetil-CoA en butiril-CoA y se usa en las células de la mucosa del colon. ${ }^{29}$

En general, se producen hasta $500-600 \mathrm{mmoL} / \mathrm{L}$ de estos constituyentes, en el intestino por día, que depende del contenido de fibra consumida en la dieta, la composición de la microbiota y el tiempo del tránsito intestinal. ${ }^{30}$ Estos ácidos grasos, en su mayoría son absorbidos por el epitelio colónico o metabolizados por otras bacterias colónicas, por difusión pasiva o transporte mediado por el transportador de monocarboxilato 1 , y solo el 5.00$10.00 \%$ son excretados en las heces. ${ }^{31}$ Se ha informado que las concentraciones en plasma; del ácido acético, propiónico y butírico son de 25-250 $\mu \mathrm{M}, 1.4-13.4 \mu \mathrm{M}$ y 0.5-14.2 $\mu \mathrm{M}$ respectivamente. ${ }^{11}$

Por otra parte, los ácidos grasos de cadena media que comprenden el ácido caprílico (C8:0) y cáprico (C10:0), se encuentran como triacilglicéridos de cadena media ${ }^{32}$ y por reacciones de hidrólisis en el intestino, se absorben directamente en la vena porta hacia el hígado en donde se metabolizan, no se reesterifican, por lo tanto, ingresan a las mitocondrias fácilmente por difusión pasiva ${ }^{33}$, donde son metabolizados dentro de las mitocondrias hepáticas, produciendo cuerpos cetónicos [3- $\beta$-hidroxibutirato $(\beta \mathrm{HB})$, ácido acetoacético (AcAc) y acetona (Ac)]. El hígado contiene poca enzima $\beta$-cetoacil-CoA transferasa para convertir los cuerpos cetónicos a acetil-CoA, por lo que son transportados a otros tejidos como cerebro, corazón y músculo, donde se encuentra la enzima para metabolizarlos. ${ }^{34}$ Por otra parte, en términos de digestión y absorción, Wallace (2019) ${ }^{33}$ sugirió que el ácido láurico (C12:0) se comporta más como un ácido graso de cadena larga, debido a que la mayoría (70.00-75.00\%) es absorbido y transportado por los quilomicrones, en comparación con los ácidos caprílico (C8:0) y cáprico (C10:0) que son absorbidos un 5.00\%. ${ }^{33}$

\section{Microbiota intestinal y su relación con la inmunidad}

La microbiota, es el conjunto de microorganismos que son frecuentemente encontrados en varias partes del organismo, y se encuentra en una relación simbiótica comensal con el hospedador, en un individuo sano puede ayudar a la digestión del alimento, producir vitaminas y protegerlo de la colonización de otros microorganismos que pueden ser patógenos (antagonismo microbiano). ${ }^{35,36}$

En el intestino delgado y grueso de los seres humanos, se encuentran especies bacterianas que producen ácidos grasos de cadena corta, como son las bacterias del filo Bacteroides, que secretan niveles altos de ácido acético y propiónico, mientras que las del filo Firmicutes, generan cantidades grandes de ácido butírico. ${ }^{37}$

Estos metabolitos microbianos, sirven como una capa adicional de comunicación entre el huésped y la microbiota. Además, algunos de estos metabolitos, también condicionan y activan el sistema inmunológico, para aumentar la función inmune y disminuir las respuestas inflamatorias dañinas. ${ }^{38}$ Por ejemplo, en el sistema inmune, el ácido graso butírico (C4:0), promueve la diferenciación de las células T $\mathrm{CD} 4^{+}$y estimula a las $\mathrm{CD}_{103^{+}} \mathrm{DCs}$, para producir niveles altos de factor de crecimiento transformante beta (TGF- $\beta$ ), que se une al receptor acoplado a proteínas $\mathrm{G}$ (GPCR) en las células dendríticas (GPR109A) y a las células T CD4+ (GPR43) para promover la diferenciación de las células $T$ reguladoras. ${ }^{39}$ También el ácido butírico (C4:0), disminuye la autoinmunidad regulando a las células $\mathrm{T}$, a las células dendríticas (DC), a las células linfoides innatas (ILC) y los macrófagos, aumentando las citocinas antiinflamatorias (TGF- $\beta$ e IL-10) y la inhibición de la producción de citocinas proinflamatorias (IL-6, IL-12, IL$17 a$, IFN-y y TNF- $\alpha) .{ }^{12}$ Además, se ha reportado que utilizan la polarización e inducción de linfocitos que promueven la diferenciación de células T, produciendo IL17, interferón-y y/o IL-10 a través de la actividad inhibidora directa de las histonas desacetilasas (HDAC). Esta subpoblación de células T cumple una función reguladora en el control de respuestas inmunes no deseadas. ${ }^{15}$ En estudios in vitro, el ácido butírico (C4:0) ejerció una mayor influencia en el comportamiento de los leucocitos comparado con los ácidos grasos acético (C2:0) o propiónico (C3:0), además de presentar un efecto antiinflamatorio general. ${ }^{29}$

\section{Acción de los ácidos grasos de cadena corta y media en la activación de los receptores acoplados a proteínas G (GPCR) sobre la respuesta inmune}

Los ácidos grasos de cadena corta interaccionan con las células inmunes y el proceso inflamatorio, a través de dos mecanismos: por la activación de GPCR y por la inhibición de las HDAC. ${ }^{15}$

Las HDAC son una familia de proteínas que incluyen cuatro clases: I (HDAC1-3 y 8), II (HDAC4-7 y HDAC910), sirtuinas III (SIRT1-7) y IV (HDAC11), se encuentran en el citoplasma o en el núcleo de las células. ${ }^{40}$ Entre sus funciones está controlar procesos biológicos (proliferación, diferenciación y el desarrollo celular) al unirse a muchos factores de transcripción y correguladores de la transcripción. ${ }^{41}$ También regulan la expresión de genes inflamatorios, la integridad vascular y el desarrollo de enfermedades cardiovasculares, incluyendo la aterosclerosis y la sepsis. ${ }^{40}$

Los GPCR, son la familia más grande de proteínas transmembrana, y desempeñan varias funciones esenciales en la señalización celular. Una de las características de los GPCR, es llevar a cabo la homeostasis, la inmunidad y el metabolismo del intestino, a través de estos receptores con la unión de metabolitos que contienen los alimentos, como son los ácidos grasos de cadena corta, media y larga, entre otros. Estos receptores, se expresan por subconjuntos de células de los sistemas inmunológico y metabólico, la mayoría por células inmunes innatas como neutrófilos, monocitos y macrófagos, células dendríticas y eosinófilos. Se han identificado varios receptores para los ácidos grasos de cadena corta, como GPCR 41/ receptor de ácido graso libre 3 (GPR41/ FFAR3), GPR43/FFAR2, GPR109A y el 
receptor olfativo 78 , que están presentes en las células epiteliales intestinales, células inmunes y adipocitos, sus niveles de expresión difieren entre tejidos y tipos de células. ${ }^{15}$

El ácido graso butírico (C4:0) se une preferentemente a GPR41 sobre GPR43, que tiene mayores afinidades por el ácido acético y propiónico. El receptor GPR41, se expresa altamente en el páncreas, en el tejido adiposo blanco y en las células neurales, donde regula el metabolismo, y a niveles bajos en el bazo y en algunos leucocitos. ${ }^{42}$ Un estudio en las células epiteliales intestinales murinas, demostró que la activación de GPR41 indujo la señalización de la proteína quinasa, activada por mitógenos y la producción de quimiocinas y citocinas, que son las vías que regulan la inmunidad protectora y la inflamación tisular. ${ }^{43}$

Los ácidos grasos acético (C2:0) y propiónico (C3:0) tienen una mayor afinidad al GPR43, uno de los principales receptores de los ácidos grasos de cadena corta, debido a que al igual que el GPR41, requiere de una concentración baja de alrededor de $0.5 \mathrm{mM}$ para poder activarse ${ }^{44}$. En los seres humanos, los transcritos de GPR43 se expresan en los enterocitos, eosinófilos, basófilos, neutrófilos, monocitos, DC y mastocitos de la mucosa, incluyendo neutrófilos polimorfonucleares, lo que indica que dichos ácidos grasos, podrían estar involucrados en la activación de leucocitos. ${ }^{13}$ En un estudio llevado a cabo en vacas con mastitis, se reportó que el receptor GPR109A, inhibió el proceso de inflamación, disminuyendo las concentraciones de IL-6, TNF- $\alpha$ e IL-1 $\beta$, debido a las altas concentraciones de ácido butírico (C4:0) en el intestino de los rumiantes, y es un ligando para este receptor, comparado con la niacina que no alcanza el umbral requerido para activarlo. ${ }^{42}$

Los ácidos grasos de cadena media, con una longitud de cadena de 9-14 átomos de carbonos, se unen exclusivamente al receptor GPR84, expresado por el tejido adiposo y por varios tipos de leucocitos (macrófagos y neutrófilos), y su expresión aumenta en condiciones inflamatorias. ${ }^{42}$ La ausencia de GPR84 afecta selectivamente la producción de IL-4 en las células $\mathrm{T} \mathrm{CD}^{+}$, la relevancia biológica de este receptor sigue siendo poco conocida. ${ }^{43}$

\section{Ácidos grasos de cadena corta y media como precursores para inhibir los síntomas del coronavirus}

Un precursor químico, es una sustancia indispensable o necesaria para producir otra mediante diferentes reacciones con otros compuestos químicos, que constituyen una primera etapa en un proceso químico (catabolismo) y que actúan como sustrato en las etapas posteriores (anabolismo). Un ejemplo son los ácidos grasos de cadena corta y media, que presentan un efecto antiinflamatorio y antiviral respectivamente. ${ }^{45}$
Se ha indicado que el ácido butírico (C4:0) ejerce un efecto antiinflamatorio, al inhibir a las células inmunes proinflamatorias (macrófagos M1 y los neutrófilos), reduciendo así la producción de citocinas proinflamatorias, al activar a las células antiinflamatorias (macrófagos Tregs y M2). ${ }^{46}$ Además, tiene un efecto inhibidor sobre la actividad de las HDAC, que promueven la acetilación de histonas, lo cual afecta la regulación génica de la proliferación celular, la diferenciación y la respuesta inflamatoria. ${ }^{17} \mathrm{La}$ inhibición de la HDAC, puede tener una gama de efectos en la quimiotaxis, diferenciación, proliferación y apoptosis. Estudios realizados sobre células inmunes con ácidos grasos de cadena corta, han relacionado la inhibición de HDAC por estos constituyentes, y su efecto en la supresión de la respuesta inflamatoria, ${ }^{45}$ como lo reportó Wang et al. $(2017)^{47}$ en un estudio realizado con ratones con mastitis inducida con lipopolisacárido (LPS), a quienes se les suministró propionato de sodio $(2 \mathrm{mM})$ y determinaron una supresión de la producción de TNF- $\alpha$, IL-6 e IL-1 $\beta$ en las glándulas mamarias. Por otra parte, Chen et al. $(2018)^{48}$ realizaron una investigación con ratones con colitis inducida por LPS, y la administración intracolónica con TNBS y macrófagos RAW246.7, donde la administración de butirato de sodio $(5 \mathrm{mM})$, suprimió la inflamación en los ratones con TNBS e incrementó la disminución de la expresión de mediadores proinflamatorios (TNF- $\alpha$ e IL-6) en los macrófagos inducidos con LPS. Por otro lado, Magnusson et al. $(2020)^{49}$ adicionaron a la dieta de los pacientes ácido butírico (C4:0) para tratar colitis ulcerosa y se observó una disminución en los niveles de TNF- $\alpha$ e IL-10 comparado con IL-6. En otro estudio realizado por Liu et al. $(2020)^{50}$ en células de ratas con lesión inducida por $\mathrm{H}_{2} \mathrm{O}_{2}$, reportó que la adición de ácido butírico (C4:0) a una concentración de $1 \mathrm{mM}$, protegió y moduló la expresión de IL-6. Sin embargo, la dosis de $8 \mathrm{mM}$ y $16 \mathrm{mM}$ provocó apoptosis e inflamación celular. Además de eso, en un estudio en humanos, se observó en pacientes con lesión pulmonar, que la adición de ácido butírico (C4:0) a una concentración de $3 \mathrm{mmol} / \mathrm{L}$, redujo la eosinófila de las vías respiratorias y mejoró la función pulmonar deteriorada. ${ }^{51}$

En cuanto al ácido acético (C2:0), se demostró que en combinación con la mezcla de ácido propiónico (C3:0) y butírico (C4:0), a concentraciones de 200 mM, 50 mM y 5 $\mathrm{mM}$ respectivamente, reducen al receptor de ácidos grasos libres 2 (FFAR2), las cargas bacterianas locales y sistémicas, que origina la patología pulmonar reducida por la infección por el virus de la influenza A. ${ }^{52}$

Por otro lado, los ácidos grasos de cadena media ejercen funciones de barrera física, de permeabilidad e inmunológica de la piel y las mucosas, y se dice que las actividades antimicrobianas contribuyen a estas funciones protectoras. ${ }^{53}$

Los ácidos grasos de cadena media, son conocidos como agentes antimicrobianos, contra algas, hongos, protozoos, virus y bacterias Gram-positivas, debido a que alteran la bicapa fosfolipídica que rodea a los microorganismo patógenos, ${ }^{22}$ dañando y/o destruyendo 
las partículas envueltas del virus o bacterias mediante lisis celular y la interferencia en procesos celulares como la transducción y la transcripción. ${ }^{22,54,55}$ Se ha informado que el ácido láurico (C12:0) a una concentración del $8.00 \%$, presenta un mayor efecto contra Escherichia coli y Salmonella spp. ${ }^{56}$ El ácido láurico (C12:0), tiene la mayor actividad antiviral y antibacteriana, debido a que desintegra las paredes celulares bacterianas, ${ }^{56}$ como lo indicó Yang et al. (2018) ${ }^{57}$ en un estudio con Clostridium difficile, donde se evaluó su efecto inhibidor a una concentración de $0.1 \mathrm{mg} / \mathrm{mL}$, y se observó una cantidad mayor de materiales de ácido nucleico comparado con el control, lo cual indica que el ácido láurico (C12:0) daña la integridad de la membrana celular. Windianingrum et al. $(2019)^{58}$ demostraron el potencial antibacteriano del aceite de coco virgen sobre el crecimiento de Staphylococcus aureus, el cual inhibió con una concentración mínima de $200 \mu \mathrm{L}$, debido a la presencia de este componente (40-60\%), que se encuentra en su aceite en forma de ácidos grasos libres y monoglicéridos, además, de tener una actividad antibacteriana, antiviral, antifúngica, antiprotozoaria, también puede mejorar el sistema inmunológico. Por otra parte, Matsue et al. $(2019)^{53}$ determinaron la actividad microbiana del ácido láurico (C12:0) contra $S$. agalactiae, $S$. mutans, $S$. pneumoniae, S. pyogenes, S. salivarius y $S$. sanguinis, y demostraron que la adición de éste ácido a una concentración de $0.25 \mathrm{mM}$ y $2.5 \mathrm{mM}$ inhibió su proliferación. En otro estudio se determinó la capacidad del ácido láurico (C12:0) para inducir regeneración celular en células Vero inoculadas con virus Junín (JUNV), en el cual se observó que a una concentración de 250 uM, el C12:0 inhibió la etapa de maduración tardía en el ciclo de replicación del virus JUNV, un virus con estructura similar a la del SARS-CoV.2. ${ }^{59}$

El ácido caprílico (C8:0) posee un amplio espectro de actividades antimicrobianas contra virus envueltos y bacterias, en estudios in vitro. ${ }^{53}$ También presenta efectos inhibidores sobre bacterias Grampositivas y Gramnegativas, así como en hongos, lo que hace posible su uso para tratar trastornos digestivos inducidos por bacterias e infecciones por hongos. ${ }^{54}$ Se ha demostrado que el ácido caprílico (C8:0) a concentraciones de 0.001$0.07 \%$ inactiva virus envueltos, mediante una acción detergente sobre su membrana lipídica, debido a su forma no ionizada, se disocia a $\mathrm{pH}$ básico en la forma ionizada y solo la forma no ionizada es capaz de inactivar el virus, haciendo una ruptura de la capa lipídica y la muerte del virus. ${ }^{54}$

Por otra parte, la combinación del ácido caprílico (C8:0) y cáprico (C10:0) se ha reportado que inhibe el crecimiento filamentoso, la adhesión y la formación de biopelículas por hongos, como lo indicó Jadhav et al. $(2017)^{60}$ quienes realizaron un estudio con ácido caprílico $(\mathrm{C8:0)}$ y cáprico (10:0) a concentraciones de 0.25 a $2 \mathrm{mg} / \mathrm{mL}$, observando una inhibición de $C$. albicans durante su crecimiento planctónico, morfogénesis, adhesión y crecimiento de biopelículas, determinando que estos ácidos detienen el ciclo celular en las fases S y G2/M y demostrando que la inhibición del crecimiento de $C$. albicans se debió a la detención de su ciclo celular.

\section{Conclusiones}

La ingesta de ácidos grasos de cadena corta y media podría mitigar o inhibir los síntomas de la enfermedad por coronavirus, debido a que son metabolitos que condicionan y activan el sistema inmune promoviendo la diferenciación de las células $T$, ejerciendo así su efecto antiinflamatorio mediante la reducción o inhibición de la expresión de moléculas de adhesión como TNF- $\alpha$, IL-6, $\mathrm{IL}-12$ e IL-10, citocinas que se observan elevadas en pacientes graves y críticos con COVID-19 y a través de la desintegración de las paredes celulares de virus y bacterias, inhibiendo de esta manera una etapa importante en el ciclo de replicación del virus. Sin embargo, poco se ha escrito sobre su uso y efecto específico en pacientes con COVID-19, por lo que se sugiere realizar más investigaciones al respecto.

\section{Referencias}

[1] Li G, Fan Y, Lai Y, Han T, Li Z, Zhou P. Coronavirus infections and immune responses. J Med Virol. 2020; 92(4): 424-432.

[2] Weisberg E, Sattler M, Yang P, Parent A, Gray N, Griffin J. Current Therapies Under Investigation for COVID-19 Potential COVID-19 Treatments. Can J Physiol Pharmacol. 2020; 98(8): 483-489.

[3] Esakandari H, Nabi-Afjadi M, Fakkari-Afjadi J, Farahmandian N, Miresmaeili SM, Bahreini E. A comprehensive review of COVID-19 characteristics. Biol Proced Online. 2020; 22: 19.

[4] Wu C, Chen X, Cai Y, Xia J, Zhou X, Xu S, Huang H, Zhang L, Zhou X, Du C, Zhang Y, Song J, Wang S, Chao Y, Yang Z, Xu J, Zhou X, Chen D, Xiong W, Xu L, Zhou F, Jiang J, Bai C, Zheng J, Song Y. Risk Factors Associated With Acute Respiratory Distress Syndrome and Death in Patients With Coronavirus Disease 2019 Pneumonia in Wuhan, China. JAMA Intern Med. 2020; 180(7): 934-943.

[5] Suárez V, Suarez Quezada M, Oros Ruiz S, Ronquillo De Jesús E. Epidemiology of COVID-19 in Mexico: from the 27th of February to the 30th of April 2020. Rev Clin Esp. 2020; 220(8): 463-471.

[6] Song P, Li W, Xie J, Hou Y, You C. Cytokine storm induced by SARS-CoV-2. Clin Chim Acta. 2020; 509: 280-287.

[7] Bhaskar S, Sinha A, Banach M, Mittoo S, Weissert R, Kass JS, Rajagopal S, Pai AR, Kutty S. Cytokine Storm in COVID-19Immunopathological Mechanisms, Clinical Considerations, and Therapeutic Approaches: The REPROGRAM Consortium Position Paper. Front Immunol. 2020; 11: 1648.

[8] Ragab D, Salah Eldin H, Taeimah M, Khattab R, Salem R. The COVID-19 Cytokine Storm; What We Know So Far. Front Immunol. 2020; 11: 1446.

[9] Yang L, Liu S, Liu J, Zhang Z, Wan X, Huang B, Chen Y, Zhang Y. COVID-19: Immunopathogenesis and Immunotherapeutics. Sig Transduct Target Ther. 2020; 5: 128.

[10] Chen G, Wu D, Guo W, Cao Y, Huang D, Wang H, Wang T, Zhang X, Chen H, Yu H, Zhang X, Zhang M, Wu S, Song J, Chen T, Han M, Li S, Luo X, Zhao J, Ning Q. Clinical and immunological features of severe and moderate coronavirus disease 2019. J Clin Invest. 2020; 130(5): 2620-2629.

[11] Dalile B, Van Oudenhove L, Vervliet B, Verbeke K. The role of shortchain fatty acids in microbiota-gut-brain communication. Nat Rev Gastroenterol Hepatol. 2019; 16(8): 461-478.

[12] Sánchez HN, Moroney JB, Gan H, Shen T, Im JL, Li T, Taylor JR, Zan H, Casali, P. B cell-intrinsic epigenetic modulation of antibody responses by dietary fiber-derived short-chain fatty acids. Nat Commun. 2020; 11(60): 1-19.

[13] Liu H, Wang J, He T, Becker S, Zhang G, Li D, Ma X. Butyrate: A Double-Edged Sword for Health?. Adv Nutr. 2018; 9(1): 21-29. 
[14] Schönfeld P, Wojtczak L. Short- and medium-chain fatty acids in energy metabolism: the cellular perspective. J Lipid Res. 2016; 57(6): 943-54.

[15] Wang S, Wang Y, Shahidi F, Ho CT. Lipids and Health. En: Bailey AE, Shahidi F, editores. Bailey's Industrial Oil and Fat Products. USA; 2020: 1-22.

[16] Yang G, Chen S, Deng B, Tan C, Deng J, Zhu G, Yin Y, Ren W. Implication of $\mathrm{G}$ Protein-Coupled Receptor 43 in Intestinal Inflammation: A Mini-Review. Front Immunol. 2018; 9:1-6.

[17] Parada Venegas D, De la Fuente MK, Landskron G, González MJ, Quera R, Dijkstra G, Harmsen HJM, Faber KN, Hermoso, MA. Short Chain Fatty Acids (SCFAs)-Mediated Gut Epithelial and Immune Regulation and Its Relevance for Inflammatory Bowel Diseases. Front Immunol. 2019; 10: 277.

[18] Kim DB, Jang GJ, Yoo M, Lee G, Yun SS, Lim HS, Kim M, Lee S Sorbic, benzoic and propionic acids in fishery products: a survey of the South Korean market. Food Addit Contam Part A Chem Anal Control Expo Risk Assess. 2018; 35(6): 1071-1077.

[19] Hernández MAG, Canfora EE, Jocken JWE, Blaak EE. The ShortChain Fatty Acid Acetate in Body Weight Control and Insulin Sensitivity. Nutrients. 2019; 11(8): 1943.

[20] Stilling RM, van de Wouw M, Clarke G, Stanton C, Dinan TG, Cryan JF. The neuropharmacology of butyrate: The bread and butter of the microbiota-gut-brain axis? Neurochem Int. 2016; 99: 110-132.

[21] Nitbani FO, Jumina, Siswanta D, Solikhah EN. Isolation and Antibacterial Activity Test of Lauric Acid from Crude Coconut Oil (Cocos nucifera L.). Procedia Chem. 2016; 18: 132-140.

[22] Jackman JA, Boyd RD, Elrod CC. Medium-chain fatty acids and monoglycerides as feed additives for pig production: towards gut health improvement and feed pathogen mitigation.J Animal Sci Biotechnol. 2020; 11(44): 2-15.

[23] Wang J, Wang X, Li J, Chen Y, Yang W, Zhang L. Effects of Dietary Coconut Oil as a Medium-chain Fatty Acid Source on Performance, Carcass Composition and Serum Lipids in Male Broilers. AsianAustralas J Anim Sci. 2015; 28(2): 223-30.

[24] Boateng L, Ansong R, Owusu WB, Steiner-Asiedu M. Coconut oil and palm oil's role in nutrition, health and national development: $\mathrm{A}$ review. Ghana Med J. 2016; 50(3): 189-196.

[25] Efendy Goon D, Sheikh Abdul Kadir SH, Latip NA, Ab Rahim S, Mazlan M. Palm Oil in Lipid-Based Formulations and Drug Delivery Systems. Biomolecules. 2019; 9(2): 64

[26] Mancini A, Imperlini E, Nigro E, Montagnese C, Daniele A, Orrù S, Buono P. Biological and Nutritional Properties of Palm Oil and Palmitic Acid: Effects on Health. Molecules. 2015; 20(9): 1733917361.

[27] Gesteiro E, Galera-Gordo J, González-Gross M. Aceite de palma y salud cardiovascular: consideraciones para valorar la literatura. Nutr Hosp. 2018; 35(5): 1229-1242.

[28] Ciampolini M. Residue, Fiber and Subjectivity. Adv Nutr. 2016; 7(2): 420.

[29] Bailey MA, Holscher HD. Microbiome-Mediated Effects of the Mediterranean Diet on Inflammation. Adv Nutr. 2018; 9(3): 193-206.

[30] Silva YP, Bernardi A, Frozza RL. The Role of Short-Chain Fatty Acids From Gut Microbiota in Gut-Brain Communication. Front Endocrinol. 2020; 11: 1-14.

[31] Bach Knudsen KE. Microbial degradation of whole-grain complex carbohydrates and impact on short-chain fatty acids and health. Adv Nutr. 2015; 6(2): 206-13.

[32] Pujol JB, Christinat N, Ratinaud Y, Savoia C, Mitchell SE, Dioum EHM. Coordination of GPR40 and Ketogenesis Signaling by Medium Chain Fatty Acids Regulates Beta Cell Function. Nutrients. 2018; 10(4): 473.

[33] Wallace TC. Health Effects of Coconut Oil-A Narrative Review of Current Evidence. J Am Coll Nutr. 2019; 38(2): 97-107.

[34] Chatterjee P, Fernando M, Fernando B, Dias CB, Shah T, Silva R, Williams S, Pedrini S, Hillebrandt H, Gooze K, Barin E, Sohrabi HR, Garg M, Cunnane S, Martins RN. Potential of coconut oil and medium chain triglycerides in the prevention and treatment of Alzheimer's disease. Mech Ageing Dev. 2020; 186: 1-10.

[35] Corrêa-Oliveira R, Fachi JL, Vieira A, Sato FT, Vinolo MA Regulation of immune cell function by short-chain fatty acids. Clin Transl Immunology. 2016; 5(4): e73.
[36] Brown EM, Kenny DJ, Xavier, RJ. Gut Microbiota Regulation of T Cells During Inflammation and Autoimmunity. Annu. Rev Immunol. 2019; 26(37): 599-624.

[37] Haase S, Haghikia A, Wilck N, Müller DN, Linker RA. Impacts of microbiome metabolites on immune regulation and autoimmunity. Immunology. 2018; 154(2): 230-238.

[38] Kim CH. Immune regulation by microbiome metabolites. Immunology. 2018; 154(2): 220-229.

[39] Zhang Y, Zhang B, Dong L, Chang P. Potential of Omega-3 Polyunsaturated Fatty Acids in Managing Chemotherapy- or Radiotherapy-Related Intestinal Microbial Dysbiosis. Adv Nutr. 2019; 10(1): 133-147.

[40] Li M, van Esch BCAM, Wagenaar GTM, Garssen J, Folkerts G, Henricks PAJ. Pro- and anti-inflammatory effects of short chain fatty acids on immune and endothelial cells. Eur J Pharmacol. 2018; 831: $52-59$.

[41] Shukla S, Tekwani BL. Histone Deacetylases Inhibitors in Neurodegenerative Diseases, Neuroprotection and Neuronal Differentiation. Front Pharmacol. 2020; 11: 537.

[42] Tan JK, McKenzie C, Mariño E, Macia L, Mackay CR. MetaboliteSensing G Protein-Coupled Receptors-Facilitators of Diet-Related Immune Regulation. Annu Rev Immunol. 2017; 35: 371-402.

[43] Melhem H, Kaya B, Ayata CK, Hruz P, Niess JH. Metabolite-Sensing G Protein-Coupled Receptors Connect the Diet-MicrobiotaMetabolites Axis to Inflammatory Bowel Disease. Cells. 2019; 8(5): 450.

[44] Ang Z, Ding JL. GPR41 and GPR43 in Obesity and InflammationProtective or Causative?. Front Immunol. 2016; 7(28): 1-5.

[45] Kaisar MMM, Pelgrom LR, van der Ham AJ, Yazdanbakhsh M, Everts B. Butyrate Conditions Human Dendritic Cells to Prime Type 1 Regulatory T Cells via both Histone Deacetylase Inhibition and G Protein-Coupled Receptor 109A Signaling. Front Immunol. 2017; 8: 1429.

[46] Chen J, Vitetta L. The Role of Butyrate in Attenuating PathobiontInduced Hyperinflammation. Immune Netw. 2020; 20(2): e15.

[47] Wang J, Wei Z, Zhang X, Wang Y, Yang Z, Fu Y. Propionate Protects against Lipopolysaccharide-Induced Mastitis in Mice by Restoring Blood-Milk Barrier Disruption and Suppressing Inflammatory Response. Front Immunol. 2017; 8: 1108.

[48] Chen G, Ran X, Li B, Li Y, He D, Huang B, Fu S, Liu J, Wang W. Sodium Butyrate Inhibits Inflammation and MaintainsEpithelium Barrier Integrity in a TNBS-induced Inflammatory Bowel Disease Mice Model. EBioMedicine. 2018; 30: 317-325.

[49] Magnusson MK, Isaksson S, Öhman L. The Anti-inflammatory Immune Regulation Induced by Butyrate Is Impaired in Inflamed Intestinal Mucosa from Patients with Ulcerative Colitis. Inflammation. 2020; 43(2): 507-517.

[50] Liu J, Zhu H, Li B, Lee C, Alganabi M, Zheng S, Pierro A. Beneficial effects of butyrate in intestinal injury. J Pediatr Sur. 2020; 55(6): 1088-1093.

[51] Archer DL, Kramer DC. The Use of Microbial Accessible and Fermentable Carbohydrates and/or Butyrate as Supportive Treatment for Patients With Coronavirus SARS-CoV-2 Infection. Front Med (Lausanne). 2020; 7: 292.

[52] Sencio V, Barthelemy A, Tavares LP, Machado MG, Soulard D, Cuinat C, Queiroz-Junior CM, Noordine ML, Salomé-Desnoulez S, Deryuter L, Foligné B, Wahl C, Frisch B, Vieira AT, Paget C, Milligan G, Ulven T, Wolowczuk I, Faveeuw C, Le Goffic R, Thomas M, Ferreira S, Teixeira MM, Trottein F. Gut Dysbiosis during Influenza Contributes to Pulmonary Pneumococcal Superinfection through Altered Short-Chain Fatty Acid Production. Cell Rep. 2020; 30(9): 2934-2947.

[53] Matsue M, Mori Y, Nagase S, Sugiyama Y, Hirano R, Ogai K, Ogura K, Kurihara S, Okamoto S. Measuring the Antimicrobial Activity of Lauric Acid against Various Bacteria in Human Gut Microbiota Using a New Method. Cell Transplant. 2019; 28(12): 1528-1541.

[54] Li Y. The application of caprylic acid in downstream processing of monoclonal antibodies. Protein Expr Purif. 2019; 153: 92-96.

[55] Solano R, Sierra C, Murillo M. Antifungal activity of LDPE/lauric acid films against Colletotrichum tamarilloi. Food Packag Shelf Life. 2020; 24: 1-8.

[56] Anzaku AA, Ishaku JI, Juliet A, Obianuju EC. Antibacterial Activity of Lauric Acid on Some Selected Clinical Isolates. Ann Clin Lab Res. 2017; 5(2), 1-5. 
Publicación semestral, Educación y Salud Boletín Científico Instituto de Ciencias de la Salud Universidad Autónoma del Estado de

Hidalgo, Vol. 9, No. 18 (2021) 224-231

[57] Yang HT, Chen JW, Rathod J, Jiang YZ, Tsai PJ, Hung YP, Ko WC, Paredes-Sabja D, Huang IH. Lauric Acid Is an Inhibitor of Clostridium difficile Growth in Vitro and Reduces Inflammation in a Mouse Infection Model. Front Microbiol. 2018; 8: 2635.

[58] Widianingrum DC, Noviandi CT, Salasia, SIO. Antibacterial and immunomodulator activities of virgin coconut oil (VCO) against Staphylococcus aureus. Heliyon. 2019; 5(10): 1-5.

[59] Soliman S, Faris M, E, Ratemi Z, Halwani R. Switching Host Metabolism as an Approach to Dampen SARS-CoV-2 Infection. Ann Nutr Metab. 2020: 1-7.

[60] Jadhav A, Mortale S, Halbandge S, Jangid P, Patil R, Gade W, Kharat K, Karuppali SM. The Dietary Food Components Capric Acid and Caprylic Acid Inhibit Virulence Factors in Candida albicans Through Multitargeting. J Med Food. 2017; 20(11): 1083-1090. 